\title{
Brain-Targeted (Pro) Renin Receptor Knockdown Modulates Body Fluid Homeostasis
}

\author{
Theresa $\mathrm{CaO}^{1^{*}}$, Wencheng $\mathrm{Li}^{2 \#}$, Dale Seth ${ }^{1 \#}, \mathrm{~L}$ Gabriel Navar ${ }^{1 \#}$ and Yumei Feng ${ }^{2 \#}$ \\ \#Authors contributed equally \\ ${ }^{1}$ Department of Physiology, Tulane University School of Medicine, Tulane Hypertension and Renal Center of Excellence, New Orleans, LA, USA \\ ${ }^{2}$ Department of Biomedical Sciences, Center for Cardiovascular Research, Colorado State University, Fort Collins, USA
}

*Corresponding author: Yumei Feng, Department of Biomedical Sciences, Center for Cardiovascular Research, Colorado State University, 1617 Campus Delivery, Fort Collins, CO, 80523, Tel: 970 4913427; E-mail: Yumei.feng@colostate.edu

Received date: June 05, 2014; Accepted date: July 17, 2014; Published date: July 21, 2014

Copyright: (C) 2014 Cao T, et al. This is an open-access article distributed under the terms of the Creative Commons Attribution License, which permits unrestricted use, distribution, and reproduction in any medium, provided the original author and source are credited.

\begin{abstract}
Objectives: The (pro) renin receptor (PRR) is highly expressed in the brain and is involved in the central regulation of blood pressure. However, the role of the brain PRR in regulating body fluid homeostasis in hypertension remains unclear. We hypothesized that the brain PRR knockdown modulates water intake, urine, and urinary sodium excretion in the context of angiotensin II (Ang II)-induced hypertension.

Methods and Results: Brain PRR was knocked down in non-transgenic (NT) normotensive and human reninangiotensinogen double-transgenic (RA) mice by intracerebroventricular (ICV) injection of adeno-associated virus expressing short hairpin RNA targeting the PRR (AAV-PRR-shRNA). Water and food intake, and urinary excretion were recorded using metabolic cages. At baseline, RA mice exhibited higher water intake, food intake, urine excretion, urinary sodium excretion and potassium excretion compared to NT mice. PRR knockdown in the brain significantly decreased water and food intake, and urinary potassium and sodium excretion in RA mice, but had no such effects in NT mice. PRR knock down also decreased reactive oxygen species generation and plasma Ang II concentration in RA mice.
\end{abstract}

Conclusion: PRR knockdown modulates body fluid homeostasis in hypertensive RA mice, suggesting that the brain PRR plays a role in regulating body fluid homeostasis during Ang Il-dependent hypertension.

\section{Introduction}

The renin-angiotensin system (RAS) has long been established as the primary mechanism of hypertension through increased levels of angiotensin (Ang) II and its subsequent effects on sympathetic activity, arterial vasoconstriction, water reabsorption and sodium retention, among other actions [1]. However, the existence of locally produced Ang II by the RAS in the brain has been a matter of debate owing to the lack of local renin [2-5]. Recent studies, however, have provided evidence that Ang II is produced in the brain [6,7] and have established an important role for brain Ang II in the secretion of the pressor agent, arginine vasopressin (AVP); thus, in addition to circulating levels of Ang II [5], brain Ang II is a contributor to hypertension.

Renin is the rate limiting enzyme that cleaves angiotensinogen, initiating a cascade that leads to the production of Ang II and subsequent regulation of water and food intake [8], AVP secretion [9], and sympathetic activation [10]. Recent studies have suggested that a new component the (pro) renin receptor (PRR) - participates in Ang II generation in vitro and in vivo [6,7,11-13] as well as AVP secretion $[6,14]$. We previously reported that knockdown of the PRR in human renin and angiotensinogen double-transgenic (RA) mice contributes to a decrease in blood pressure(BP) in this Ang II-dependent hypertensive model [6]. However, the effects of the PRR on metabolic rate and body fluid homeostasis during hypertension have not been explored.
In the current study, we used the RA mouse model, in which the brain RAS is known to contribute to the development of hypertension [15], to investigate the effect of brain PRR knockdown on body fluid homeostasis in Ang II-dependent hypertension.

\section{Materials and Methods}

\section{Animals}

Breeder mice singly transgenic for human renin (R) or human angiotensinogen (A) were generated at the University of Iowa Transgenic Animal Facilities (generous gifts from Dr. Curt D. Sigmund). R and A mice were bred to produce double-transgenic human renin and human angiotensinogen (RA) offspring. Only 8-10week-old RA mice and their non-transgenic (NT) littermates were used in these experiments. All procedures were approved by the Institutional Animal Care and Use Committees of Tulane University School of Medicine and Colorado State University.

\section{Construction and production of AAV-PRR-shRNA}

Short hairpin RNA (shRNA) designed to target mouse PRR mRNA translation was ligated and cloned into an adeno-associated virus (AAV-2) vector tagged with green fluorescent protein (GFP), as described previously [6]. All vector packaging was performed by the 
University of Iowa Gene Transfer Vector Core using the baculovirus system.

\section{BP measurement}

Systolic BP of mice in both RA and NT groups was measured by the tail-cuff method using a Visitech BP-2000 system (Visitech Systems, Apex, NC) adjusted for mice. Values were used only if at least 10 recorded measurements were valid. The values were then averaged and analyzed. Pressure values were recorded on two consecutive days for baseline values and then again 14 days after intracerebro ventricular (ICV) microinjection of AAV-PRR-shRNA.

\section{Brain-targeting AAV-PRR-shRNA by ICV microinjection}

Mice from both RA and NT groups were anesthetized with 3\% isoflurane (IsoSol; Abbo Laboratories, Chicago, IL) and continuously maintained on $1-1.5 \%$ isofluraneusing a vaporizer. Mice were then placed in a stereotaxic apparatus (Stoelting Co., Wood Dale, IL) and ICV-microinjected $(0.3 \mathrm{~mm}$ posterior to bregma, $1.0 \mathrm{~mm}$ to the right from midline, $3.3 \mathrm{~mm}$ from the top of the brain) with $200 \mathrm{~nL}$ of an AAV-PRR-shRNA solution $\left(3.5 \times 10^{11}\right.$ vector genomes $\left.(\mathrm{Vg}) / 100 \mathrm{~nL}\right)$ as previously described [6]. Mice were then returned to their home cages and allowed to recuperate for 48 hours before resuming collection of metabolic cage data; 48 -hour resting periods were allowed between data-collection cycles.

\section{Metabolic cage recordings}

Mice were placed in metabolic cages for 24 hours and then returned to their home cages for a 24 hour rest period. Food allocated to each mouse was weighed at the initial time of placement and then rerecorded after 24 hours. The difference between the weights of food was calculated to determine food intake. Water intake (via water dispensers) and changes in body weight were also recorded similarly. Urine samples were collected after 24 hours and stored in 2-mL tubes at $-20^{\circ} \mathrm{C}$.

\section{Urine electrolyte and osmolality analyses}

Twenty-four-hour urine samples were collected (3x dilution factor) at baseline and 14 days after AAV-PRR-shRNA ICV injection. Urinary sodium and potassium concentrations and osmolality were measured using flame photometry. Twenty-four-hour urinary sodium and potassium excretion were calculated according to the following: $\mathrm{mmol} / 24 \mathrm{~h}=\mathrm{mmol} / \mathrm{L} \times \mathrm{L} / 1000 \mathrm{~mL} \times \mathrm{mL} / 24 \mathrm{~h}$. Twenty-four-hour urinary osmolality was analyzed using the original units of $\mathrm{mmol} / \mathrm{kg}$ using a VAPRO vapor pressure Osmometer (WescorInc, Logan, UT).

\section{Measurement of plasma and kidney Ang II}

Ang II concentrations in plasma and kidney were measured using a previously described radioimmunoassay [16,17]. Briefly, after recording volumes and weights, kidneys from NT and RA mice obtained 14 days after AAV-GFP or AAV-PRR-shRNA injection were homogenized in the presence of a proteinase inhibitor cocktail and then transferred to excess ice-cold methanol to denature the proteins. Plasma was obtained from blood samples by centrifugation using standard procedures. The samples were quickly vortexed and centrifuged at $4,000 \mathrm{rpm}$ at $4^{\circ} \mathrm{C}$ for 30 minutes, and the supernatants were decanted and vacuum dried. The pellets were reconstituted in radioimmunoassay (RIA) buffer and assayed in duplicate $(100 \mu \mathrm{L}$ samples). Each sample mixture contained $100 \mu \mathrm{L}$ anti-Ang II antibody (RIA antibody; Peninsula Laboratories, San Carlos, CA) and $100 \mu \mathrm{L}$ 125I-Ang II (initial activity, 15,000 CPM/100 $\mu \mathrm{L}$; Perkin-Elmer, Waltham, MA). The samples were incubated along with Ang II standards for 48 hours at $4^{\circ} \mathrm{C}$. Bound and free radiolabels were separated from each other by addition of dextran-charcoal and centrifugation, and bound activity was counted on a Wallac-Wizard 1470 Automatic Gamma Counter. Sample CPMs were plotted against the Ang II standard curve to yield fmoles $/ \mathrm{mL}$ or fmoles/g.

\section{Fluorogenic monitoring of superoxide production}

The brains from NT and RA mice were rapidly dissected 14 days after AAV-GFP or AAV-PRR-shRNA injection, frozen in optimum cutting temperature (OCT) compound and stored at $80^{\circ} \mathrm{C}$ until use. Brains were cryostat-sectioned to a thickness of $25 \mu \mathrm{m}$ and directly mounted onto chilled microscope slides. Sections were thawed at room temperature, rehydrated with phosphate-buffered saline (PBS), and incubated with the fluorogenic probe dihydroethidium (DHE; 1 $\mu \mathrm{M}$ in PBS) for 5 minutes in the dark. After incubation, sections were washed three times with PBS (3 minutes each). Following the final wash, sections were cover slip-mounted and imaged with a fluorescence microscope (Zeiss LSM 510) using an excitation wavelength of $543 \mathrm{~nm}$ and a rhodamine emission filters. DHE fluorescence was quantified by a separate investigator using Image J (version 1.31) NIH analysis software.

\section{RNA isolation and real-time reverse transcription PCR}

Kidney and heart from NT and RA mice 14 days after AAV-PRRshRNA or AAV-eGFP injection were harvested and total RNA was isolated using a standard RNA extraction procedure with RN easy mini kit (Qiagen Technologies, Hilden, Germany). Total RNA was quantified using a Spectrophotometer (Thermo Scientific Nanodrop 2000). $200 \mathrm{ng}$ total RNA was used for cDNA synthesis using cDNA reverse transcription kit (Applied Biosystems, Foster City, CA). Specific primers for mouse PRR (Fwd: 5'-TCT CTC CGA ACT GCA AGT GCA ACA-3'; Rev: 5'-CCA AAC CTG CCA GCT CCA ATG AAT-3') and internal control mouse GAPDH (Fwd: 5'-AAT GTG TCC GTC GTG GAT CTG A-3'; Rev: 5'-GAT GCC TGC TTC ACC ACC TTC T-3') were designed using Primer Quest Software (Integrated DNA Technologies, Coralville, IA). Real-time reverse transcription PCR was performed using the SYBR green qPCR master mix (USB Corporation, Cleveland, $\mathrm{OH}$ ) following the manufacturer's instruction. Cycling conditions were $95^{\circ} \mathrm{C}$ for $10 \mathrm{~min}$ and then 40 cycles consisting of $15 \mathrm{sec}$ at $95^{\circ} \mathrm{C}, 60 \mathrm{sec}$ at $60^{\circ} \mathrm{C}$ and $30 \mathrm{sec}$ at $72^{\circ} \mathrm{C}$. Relative expression was calculated using the $2-\Delta \Delta \mathrm{CT}$ method. Values were expressed as the ratio to NT mice with control virus administration. The expression levels of targeted mRNAs were normalized based on the expression levels of GAPDH mRNA.

\section{Statistical analysis}

Data were expressed as means \pm SEM and analyzed by Student's $t$ test, two-way, or one-way analysis of variance (ANOVA) with Bonferroni post hoc tests to compare replicate means, as appropriate. Statistical comparisons were performed using Prism5 (Graph Pad Software). Differences were considered statistically significant at $\mathrm{P}<0.05$. 
Citation: $\quad$ Cao T, Li W, Seth D, Navar LG, Feng Y (2014) Brain-Targeted (Pro) Renin Receptor Knockdown Modulates Body Fluid Homeostasis. J

Page 3 of 6

\section{Results}

\section{Brain-targeted PRR knockdown decreases BP in RA mice}

As showed in Figure 1A, baseline mean arterial pressure (MAP) was significantly higher in RA mice $(145.3 \pm 4.28)$ than in NT mice $(108.7$ $\pm 2.99 \mathrm{mmHg})$. PRR knockdown significantly decreased MAP in RA mice 2 weeks after AAV-PRR-shRNA injection, reducing it from baseline levels $(145.3 \pm 4.28 \mathrm{mmHg})$ to $124.2 \pm 4.71 \mathrm{mmHg}$. However, MAP remained significantly higher in AAV-PRR-shRNA-injected RA mice compared to NT mice ICV-injected with AAV-PRR-shRNA $(100.2 \pm 6.31 \mathrm{mmHg})$. Notably, PRR knockdown had no effect on BP in NT mice.
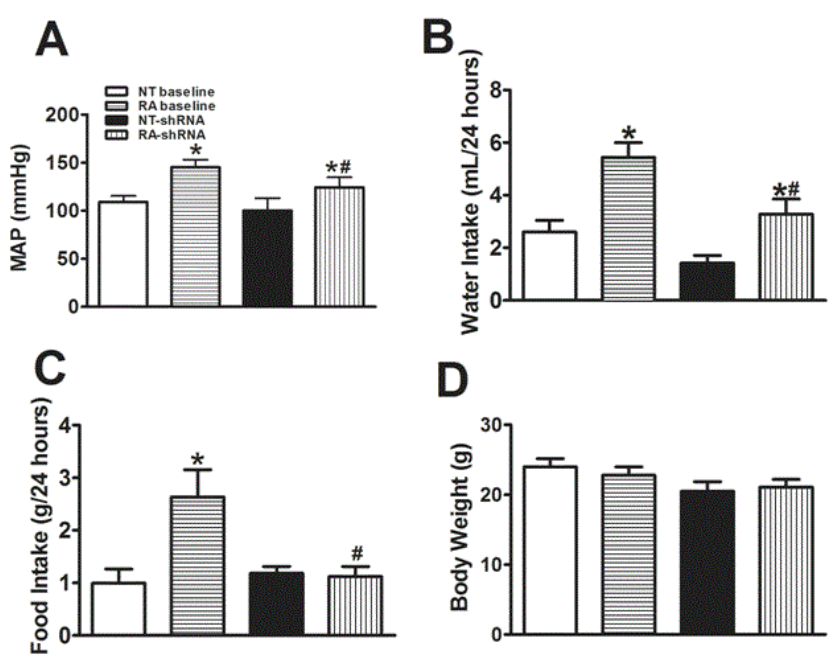

Figure 1: Effect of PRR knockdown on BP, water and food intake, and body weight. (A) MAP of NT and RA mice at baseline and 14 days after ICV injection of AAV-PRR-shRNA. (B) Water intake by NT and RA mice at baseline and 14 days after ICV injection of AAV-PRR-shRNA. (C) Food intake by NT and RA mice at baseline and 14 days after ICV injection of AAV-PRR-shRNA. (D) Body weight of NT and RA mice at baseline and 14 days after ICV injection of AAV-PRR-shRNA. ( $\mathrm{n}=6$ /group; ${ }^{\star} \mathrm{P}<0.05$ vs. NT baseline, $\# \mathrm{P}<0.05$ vs. $\mathrm{RA}$ baseline)

\section{Brain-targeted PRR knockdown reduces food and water intake in RA mice}

As shown in Figure 1B, baseline water intake by RA mice $(5.44 \pm$ $0.56 \mathrm{~mL} / 24 \mathrm{~h})$ was higher than that in NT mice $(2.60 \pm 0.45 \mathrm{~mL} / 24 \mathrm{~h})$. ICV delivery of AAV-PRR-shRNA significantly reduced 24 hour water intake in RA mice $(3.28 \pm 0.57 \mathrm{~mL} / 24 \mathrm{~h})$ compared to baseline values, although water intake remained higher than that in NT mice receiving AAV-PRR-shRNA $(1.42 \pm 0.28 \mathrm{~mL} / 24 \mathrm{~h})$. Interestingly, food intake at baseline was higher in RA mice $(2.63 \pm 0.52 \mathrm{~g} / 24 \mathrm{~h})$ than in NT mice $(0.99 \pm 0.27 \mathrm{~g} / 24 \mathrm{~h}$; Figure 1C). ICV injection of AAV-PRR-shRNA normalized food intake in RA, restoring it to a level that was not significantly different from that in NT mice $(1.55 \pm 0.46$ vs. $1.18 \pm$ $0.136 \mathrm{~g} / 24 \mathrm{~h}$ ). Despite increased daily food intake in RA mice, body weight (Figure 1D) was not significantly different between RA mice $(22.80 \pm 1.19 \mathrm{~g})$ and NT mice $(23.96 \pm 1.21 \mathrm{~g})$ at baseline. ICV injection of AAV-PRR-shRNA did not alter body weight in RA or NT mice $(21.07 \pm 1.12$ vs. $20.52 \pm 1.33 \mathrm{~g})$.

\section{Effects of brain-targeted PRR knockdown on body fluid homeostasis during Ang II-dependent hypertension}

Urine excretion was higher in RA mice $(3.33 \pm 0.54 \mathrm{~mL} / 24 \mathrm{~h})$ than in NT mice $(1.88 \pm 0.09 \mathrm{~mL} / 24 \mathrm{~h})$ at baseline (Figure $2 \mathrm{~A}$, day 0 ). This increase in urine volume was associated a significant decrease in urine osmolality in RA mice $(913.3 \pm 85.33 \mathrm{mmol} / \mathrm{kg}$; Figure $2 \mathrm{~B})$ compared to NT mice $(1376 \pm 89.76 \mathrm{mmol} / \mathrm{kg})$. ICV-delivered AAV-PRRshRNA produced a trend toward decreased urine excretion in RA mice on day 11, but this difference did not reach significance. AAV-PRRshRNA had no effect on osmolality in RA or NT mice. Baseline urinary sodium concentration was lower in RA mice than in NT mice $(0.063 \pm 0.007$ vs. $0.104 \pm 0.004 \mathrm{mM})$; potassium concentration was similarly decreased in RA mice $(0.142 \pm 0.015 \mathrm{mM})$ compared to NT mice $(0.197 \pm 0.019 \mathrm{mM})$. AAV-PRR-shRNA had no effect on urinary sodium or potassium concentration (Figure $2 \mathrm{C}$ and $2 \mathrm{D}$ ).

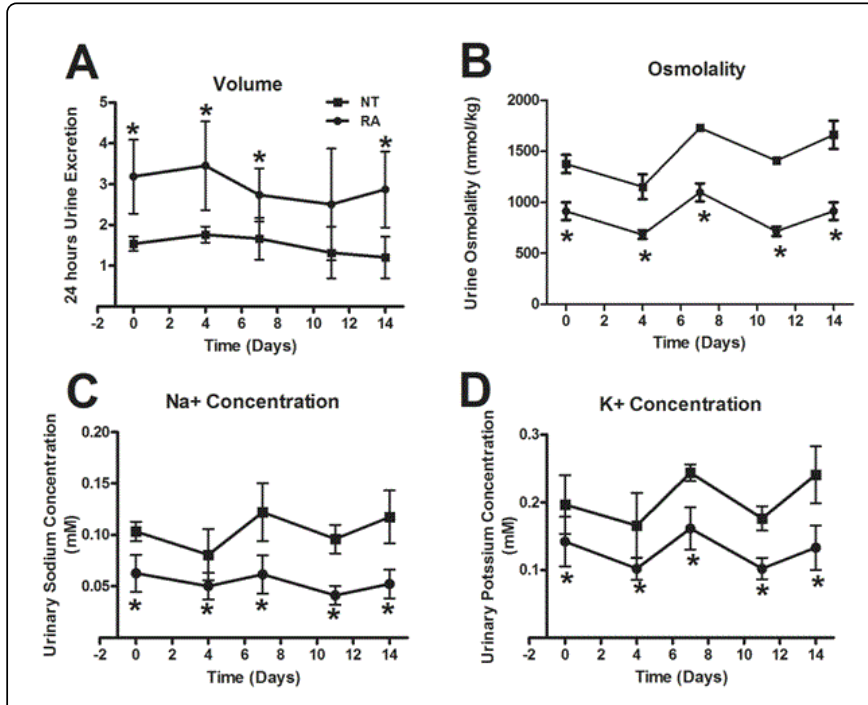

Figure 2: Effects of brain-targeted PRR knockdown on body fluid homeostasis. (A) Twenty-four-hour urinary excretion in NT and RA mice at baseline (day 0 ) and after ICV injection of AAV-PRRshRNA. (B) Urinary osmolality in NT and RA mice at baseline and after ICV injection of AAV-PRR-shRNA. (C) Urinary sodium concentration in NT and RA mice at baseline and after ICV injection of AAV-PRR-shRNA. (D) Urinary potassium concentration in NT and RA mice at baseline and after ICV injection of AAV-PRR-shRNA. 

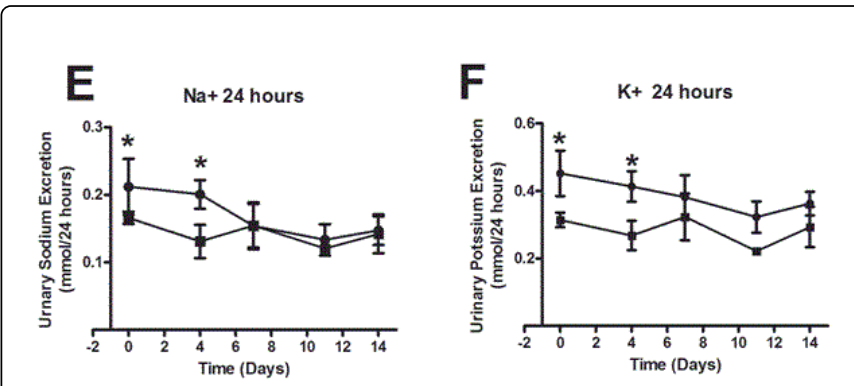

(E) Twenty-four-hour urinary sodium excretion in NT and RA mice at baseline and after ICV injection of AAV-PRR-shRNA. (F) Twenty-four-hour urinary sodium excretion in NT and RA mice at baseline and after ICV injection of AAV-PRR-shRNA. (n=6/group; ${ }^{\star} \mathrm{P}<0.05$ vs. NT).

Interestingly, urinary sodium and potassium excretion were greater in RA mice $(0.22 \pm 0.03$ and $0.46 \pm 0.07 \mathrm{mmol} / 24 \mathrm{~h}$, respectively) than in NT mice (0. $0.17 \pm 0.01$ and $0.31 \pm 0.02 \mathrm{mmol} / 24$ hours, respectively) at baseline. AAV-PRR-shRNA completely normalized this increase in urinary sodium and potassium excretion beginning 7 days after ICV injection.

\section{Effects of brain-targeted PRR knockdown on plasma and kidney Ang II levels}

We previously reported that ICV delivery of AAV-PRR-shRNA decreases Ang II levels in the hypothalamus of RA mice [18] in association with a decrease in BP [6]. To determine the effect of braintargeted PRR knockdown outside the brain, we measured plasma and kidney Ang II levels. In RA mice treated with control virus, Ang II levels were significantly elevated in the plasma (446.2 \pm 163.2 $\mathrm{fmol} / \mathrm{mL})$ and the kidney $(1673 \pm 130.8 \mathrm{fmol} / \mathrm{g})$ compared to NT mice injected with control virus (Figure $3 \mathrm{~A}$ and $\mathrm{B}$ ). Brain-targeted PRR knockdown decreased Ang II levels in the plasma (136.2 $\pm 37.5 \mathrm{fmol} /$ mLvs. RA+AAV-GFP), but not in the kidneys of RA mice. ICV injection of AAV-PRR-shRNA had no effect on Ang II levels in the plasma or kidney in NT mice.
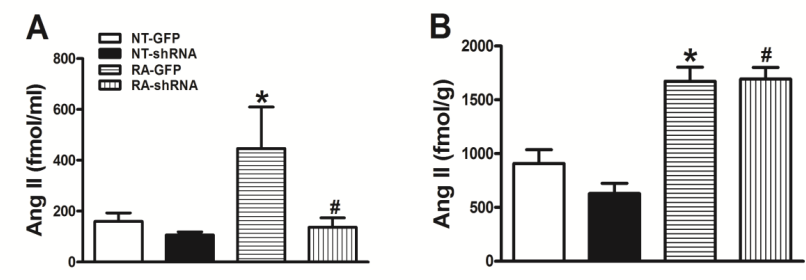

Figure 3: Brain-targeted PRR knockdown decreases plasma Ang II levels. (A) Plasma Ang II levels in NT and RA mice 14 days after AAV-GFP or AAV-PRR-shRNA treatment. (B) Kidney Ang II levels in NT and RA mice 14 days after AAV-GFP or AAV-PRRshRNA treatment. ( $\mathrm{n}=6$ /group; ${ }^{*} \mathrm{P}<0.05$ vs. NT-GFP, $\# \mathrm{P}<0.05$ vs. RA-GFP).

\section{ICV delivery of AAV-PRR-shRNA reduces oxidative stress in the subfornical organ of RA mice}

To determine whether the altered body fluid homeostasis in RA mice was associated with increased oxidative stress in the CNS, we examined fluorescence of the reactive oxygen probe, DHE, throughout the brain. Following treatment with control (AAV-GFP) vector, DHE fluorescence, measured as relative fluorescence units (RFU), was higher in the subfornical organ (SFO) of RA mice (1.8 \pm 0.2 -fold) than in that of NT mice, where only low-level DHE staining was observed (Figure 4A and B). Brain-targeted PRR knockdown significantly attenuated the increase in DHE fluorescence in the SFO of RA mice (fold change in RFU: $1.3 \pm 0.1$ vs. RA+AAV-GFP). In contrast, AAVPRR-shRNA had no effect on DHE fluorescence in NT mice.

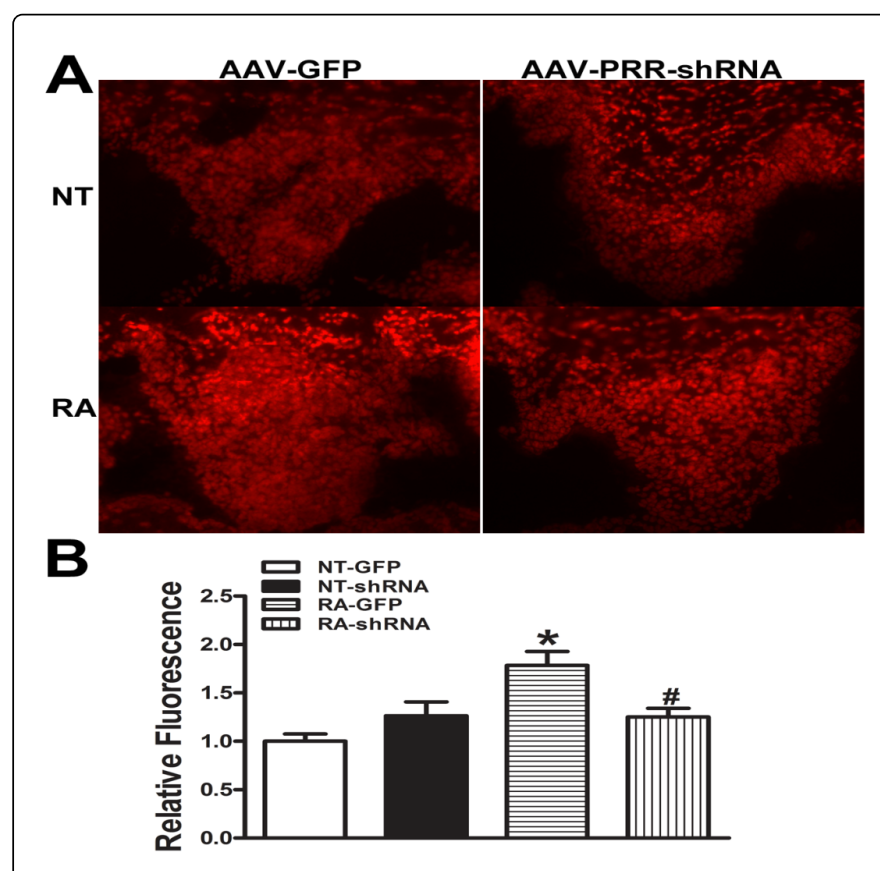

Figure 4: ICV delivery of AAV-PRR-shRNA reduces oxidative stress in the SFO of RA mice. (A) Representative DHE staining in the SFO of NT and RA mice 14 days after AAV-GFP or AAV-PRRshRNA treatment. (B) Quantification of DHE staining in NR and RA mice 14 days after AAV-GFP or AAV-PRR-shRNA treatment. ( $\mathrm{n}=6 /$ group; ${ }^{\star} \mathrm{P}<0.05$ vs. NT-GFP, $\# \mathrm{P}<0.05$ vs. RA-GFP).

\section{ICV injection of AAV-PRR-shRNA has no effect on PRR mRNA levels in the kidney and heart}

We previously reported that ICV delivery of AAV-PRR-shRNA reduced the PRR mRNA levels in the SFO without affecting PRR expression in other brain nuclei including the paraventricular nucleus or supraoptic nucleus [6]. To investigate whether ICV injection of AAV-PRR-shRNA affects PRR expression in other peripheral organs, PRR mRNA was measured in the kidney and heart after ICV injection of AAV-GFP or AAV-PRR-shRNA in NT and RA mice. PRR mRNA levels were increased in the kidney (Figure $5 \mathrm{~A}$ ) and heart (Figure $5 \mathrm{~B}$ ) of the RA mice when treated with AAV-GFP compared to NT mice with the same treatment. ICV injection of AAV-PRR-shRNA did not affect PRR mRNA in the kidney and heart in either RA or NT mice. 
A

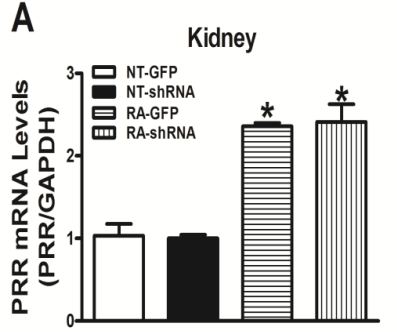

B

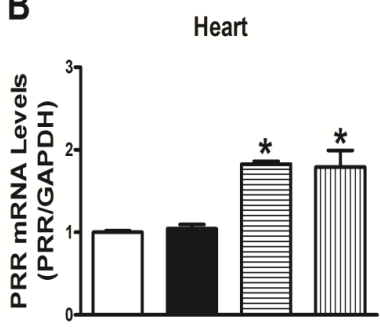

Figure 5: ICV injection of AAV-PRR-shRNA has no effect on PRR mRNA levels in the kidney or heart. (A) PRR mRNA levels in the kidney of RA and NT mice 14 days after ICV injection of AAVGFP or AAV-PRR-shRNA. (B) PRR mRNA levels in the heart of RA and NT mice 14 days after ICV injection of AAV-GFP or AAVPRR-shRNA. ( $\mathrm{n}=5$ /group; ${ }^{*} \mathrm{P}<0.05$ vs. NT-GFP).

\section{Discussion}

Increases in brain Ang II are associated with an increase in metabolic rate in mice [19]. Consistent with this, metabolic rates in hypertensive mice through activation of the brain RAS are higher than those in normotensive mice [20]. In the current study, we found that hypertensive RA mice exhibited greater food and water intake, whereas, their body weights were similar to those of NT mice. Although resting metabolic rates were not measured in these mice, we would predict that metabolic rates are higher in RA mice. We previously reported that PRR deletion in the brain prevents Ang II formation and thus activation of the brain RAS [6,7]. Importantly, selective PRR knock down in the brain significantly reduced food and water intake in hypertensive RA mice, suggesting the functional importance of the PRR and brain RAS in the regulation of food intake. This finding is in agreement with a previous report from Grobe and colleagues that activation of the brain RAS is essential for increasing metabolism [21]. In contrast, PRR knockdown did not affect the homeostasis in normotensive mice. These findings are consistent with previous study showing that PRR knockdown in the brain did not change the blood pressure in normotensive mice [6]. No effect of PRR knockdown on body fluid homeostasis in normotensive mice was possibly due to the redundant mechanisms in maintaining normal homeostasis in physiological conditions.

Urine excretion is regulated by multiple components of the reninangiotensin-aldosterone system, including the renal sympathetic nervous system [22], plasma aldosterone [23], plasma Ang II [24], and AVP excretion [25-28]. We previously reported that brain-targeted PRR knockdown decreases plasma AVP levels [6], which would suggest that the urinary volume excreted should be higher. However, total urine excretion remained similar before and after brain-targeted PRR knock down, possibly due to the reduction in water intake in RA mice after PRR knock down. Sodium excretion is regulated by intrarenal pressure, the intrarenal RAS, and the renal sympathetic system $[27,29,30]$. Interestingly, we unexpectedly found a reduction in plasma Ang II levels following PRR knockdown with no alteration in kidney Ang II levels. It is possible that the reduction in plasma Ang II is related to a reduction in renal sympathetic activity, consistent with our previous report that PRR knockdown in the brain reduces cardiac and vasomotor sympathetic tone [6]. Thus, the reduction in BP following PRR knockdown may be a major contributor to the reduction in 24 hour sodium and potassium excretion.

Reactive oxygen species (ROS) generation has been identified as an important signalling mechanism in Ang II action. Overproduction of ROS in the vasculature has been implicated in the pathogenesis of hypertension caused by systemic Ang II infusion [31]. In the CNS, ROS are best known for their role in the pathogenesis of primary neurodegenerative diseases, such as amyotrophic lateral sclerosis [32] and Alzheimer's disease [33]. However, Zimmerman and colleagues have reported the involvement of ROS as second messengers in Ang II-induced signaling in the CNS [34]. Using adenoviral vectormediated expression of superoxide dismutase (AdSOD), they found that injection of Ang II elicited changes in BP, heart rate, and drinking in the CNS-changes that were abolished by prior treatment with AdSOD. A subsequent study demonstrated that chronic infusion of Ang II over a 2-week period was correlated with marked elevations in ROS production specifically in the SFO [35]. More importantly, ICV injection of AdSOD decrease sdROS formation in the SFO and was associated with attenuation of hypertension induced by Ang II infusion. Collectively, these reports suggest that ROS is an important downstream signal for brain Ang II regulation of BP and drinking responses. In our previous report, we found that Ang II levels in the hypothalamus were decreased in RA mice after PRR knockdown [18]. This decrease in Ang II levels may contribute to the reduction in ROS formation observed in current study, placing ROS in a position to act as the mediator between PRR knockdown and body fluid homeostasis in RA mice.

In summary, the brain PRR affects metabolic rate and body fluid homeostasis in Ang II-dependent hypertensive mice through regulation of Ang II, ROS, and AVP formation. These data suggest that the PRR plays a regulatory role in body fluid homeostasis during hypertension.

\section{Acknowledgements}

We thank Dr. Curt D. Sigmund from the University of Iowa for the generous gift of transgenic mice.

\section{Sources of Funding}

The work was supported in part by a grant from the American Heart Association (11SDG7360050) to Y. Feng and by the COBRE grant from NIGMS (P30GM103337) to L.G. Navar.

\section{References}

1. Reid IA, Morris BJ, Ganong WF (1978) The renin-angiotensin system. Annu Rev Physiol 40: 377-410.

2. Reid IA (1977) Is there a brain renin-angiotensin system? Circ Res 41: 147-153.

3. Grobe JL, Xu D, Sigmund CD (2008) An intracellular renin-angiotensin system in neurons: fact, hypothesis, or fantasy. Physiology (Bethesda) 23: 187-193.

4. Bader M, Peters J, Baltatu O, Müller DN, Luft FC, et al. (2001) Tissue renin-angiotensin systems: new insights from experimental animal models in hypertension research. J Mol Med (Berl) 79: 76-102.

5. Bader M, Ganten D (2002) It's renin in the brain: transgenic animals elucidate the brain renin angiotensin system. Circ Res 90: 8-10.

6. Li W, Peng H, Cao T, Sato R, McDaniels SJ, et al. (2012) Brain-targeted (pro) renin receptor knockdown attenuates angiotensin II-dependent hypertension. Hypertension 59: 1188-1194. 
7. Li W, Peng H, Mehaffey EP, Kimball CD, Grobe JL, et al. (2014) Neuronspecific (pro)renin receptor knockout prevents the development of saltsensitive hypertension. Hypertension 63: 316-323.

8. Johnson AK, Thunhorst RL (1997) The neuroendocrinology of thirst and salt appetite: visceral sensory signals and mechanisms of central integration. Front Neuroendocrinol 18: 292-353.

9. Matsukawa S, Keil LC, Reid IA (1991) Role of endogenous angiotensin II in the control of vasopressin secretion during hypovolemia and hypotension in conscious rabbits. Endocrinology 128: 204-210.

10. Reid IA (1992) Interactions between ANG II, sympathetic nervous system, and baroreceptor reflexes in regulation of blood pressure. Am J Physiol 262: E763-778.

11. Nguyen G, Delarue F, Burcklé C, Bouzhir L, Giller T, et al. (2002) Pivotal role of the renin/prorenin receptor in angiotensin II production and cellular responses to renin. J Clin Invest 109: 1417-1427.

12. Nguyen G (2011) Renin and prorenin receptor in hypertension: what's new? Curr Hypertens Rep 13: 79-85.

13. Peng H, Li W, Seth DM, Nair AR, Francis J, et al. (2013) (Pro)renin receptor mediates both angiotensin II-dependent and -independent oxidative stress in neuronal cells. PLoS One 8: e58339.

14. Shan Z, Shi P, Cuadra AE, Dong Y, Lamont GJ, et al. (2010) Involvement of the brain (pro)renin receptor in cardiovascular homeostasis. Circ Res 107: 934-938.

15. Davisson RL, Yang G, Beltz TG, Cassell MD, Johnson AK, et al. (1998) The brain renin-angiotensin system contributes to the hypertension in mice containing both the human renin and human angiotensinogen transgenes. Circ Res 83: 1047-1058.

16. Gonzalez-Villalobos RA, Seth DM, Satou R, Horton H, Ohashi N, et al (2008) Intrarenal angiotensin II and angiotensinogen augmentation in chronic angiotensin II-infused mice. Am J Physiol Renal Physiol 295: F772-779.

17. Nishiyama A, Seth DM, Navar LG (2002) Renal interstitial fluid concentrations of angiotensins I and II in anesthetized rats. Hypertension 39: 129-134.

18. Li W, Peng H, Seth DM, Feng Y (2012) The Prorenin and (Pro)renin Receptor: New Players in the Brain Renin-Angiotensin System? Int J Hypertens 2012: 290635.

19. Grobe JL, Grobe CL, Beltz TG, Westphal SG, Morgan DA, et al. (2010) The brain Renin-angiotensin system controls divergent efferent mechanisms to regulate fluid and energy balance. Cell Metab 12: 431-442.

20. Grobe JL, Buehrer BA, Hilzendeger AM, Liu X, Davis DR, et al. (2011) Angiotensinergic signaling in the brain mediates metabolic effects of deoxycorticosterone (DOCA)-salt in C57 mice. Hypertension 57: 600-607.
21. Grobe JL, Rahmouni K, Liu X, Sigmund CD (2013) Metabolic rate regulation by the renin-angiotensin system: brain vs. body. Pflugers Arch 465: 167-175.

22. Bell-Reuss E, Trevino DL, Gottschalk CW (1976) Effect of renal sympathetic nerve stimulation on proximal water and sodium reabsorption. J Clin Invest 57: 1104-1107.

23. Patel BM, Mehta AA (2012) Aldosterone and angiotensin: Role in diabetes and cardiovascular diseases. Eur J Pharmacol 697: 1-12.

24. McKinley MJ, Albiston AL, Allen AM, Mathai ML, May CN, et al. (2003) The brain renin-angiotensin system: location and physiological roles. Int J Biochem Cell Biol 35: 901-918.

25. Cao T, Feng Y (2013) The (pro)renin receptor and body fluid homeostasis. Am J Physiol Regul Integr Comp Physiol 305: R104-106.

26. Antunes-Rodrigues J, de Castro M, Elias LL, Valença MM, McCann SM (2004) Neuroendocrine control of body fluid metabolism. Physiol Rev 84: $169-208$.

27. Skøtt O (2003) Body sodium and volume homeostasis. Am J Physiol Regul Integr Comp Physiol 285: R14-18.

28. Robertson GL, Shelton RL, Athar S (1976) The osmoregulation of vasopressin. Kidney Int 10: 25-37.

29. Heinz MK, Gray DA (2001) Role of plasma ANG II in the excretion of acute sodium load in a bird with salt glands (Anas platyrhynchos). Am J Physiol Regul Integr Comp Physiol 281: R346-351.

30. Hall JE (1986) Control of sodium excretion by angiotensin II: intrarenal mechanisms and blood pressure regulation. Am J Physiol 250: R960-972.

31. Laursen JB, Rajagopalan S, Galis Z, Tarpey M, Freeman BA, et al. (1997) Role of superoxide in angiotensin II-induced but not catecholamineinduced hypertension. Circulation 95: 588-593.

32. Deng HX, Hentati A, Tainer JA, Iqbal Z, Cayabyab A, et al. (1993) Amyotrophic lateral sclerosis and structural defects in $\mathrm{Cu}, \mathrm{Zn}$ superoxide dismutase. Science 261: 1047-1051.

33. Smith MA, Richey Harris PL, Sayre LM, Beckman JS, Perry G (1997) Widespread peroxynitrite-mediated damage in Alzheimer's disease. J Neurosci 17: 2653-2657.

34. Zimmerman MC, Lazartigues E, Lang JA, Sinnayah P, Ahmad IM, et al. (2002) Superoxide mediates the actions of angiotensin II in the central nervous system. Circ Res 91: 1038-1045.

35. Zimmerman MC, Lazartigues E, Sharma RV, Davisson RL (2004) Hypertension caused by angiotensin II infusion involves increased superoxide production in the central nervous system. Circ Res 95: $210-216$ 